\title{
IDENTIFIKASI BENTUK STRUKTUR DAN PERAN HUTAN KOTA SELONG KABUPATEN LOMBOK TIMUR.
}

\author{
Oleh: \\ Ilwan, Raden Roro. Narwastu Dwi Rita \\ Program Studi Kehutanan Universitas Pendidikan Mandalika
}

\begin{abstract}
Abstrak
Adapun tujuan penelitian ini adalah 1. Untuk mengetahui identifikasin bentuk struktur ruang terbuka hiju kota hutan kota selong. 2, Untu megetahui peran hutan kota Selong bagi masyarakat kota Selong. Metodologi Penelitian : Penelitian yang dilakukan yakni penelitian dengan pendekatan kualitatif dan bersifat deskriptif, Tehnik pengumpulan data : Untuk mengetahui dan mendeskripsikan bentuk dan struktur hutan kota melalui surve lapangan. Untuk data peranan hutan kota diperoleh dengan penyebaran kuisoner kepada masyarakat sekitar kawasan, yang dipilih secara eksidentil pengunjung yang ada pada saat penelitian dilakukan, Teknik analisis data : Kuisoner terkait fungsi hutan kota yaitu: aspek ekologis, aspek lansekap dan aspek estetika, ditabulasikan dalam bentuk table sekor. Penentuan katagori penilaian dipergunakan berdasarkan skala likrets Klasifikasi penilaian ada 5 tingkat nilai 1 (sangat tidak baik), 2 (tidak baik), 3 (cukup baik), 4 (baik), 5 (sangat baik). Penentuan klas nilai ini dengan menentukan range nilai rata-rata. Range nilai rata-rata $=$ selisih nilai rata-rata tertinggi dengan nilai rata-rata terendah, sebagai dasar penentuan klasifikasi penelitian, Kesimpulan : 1. Bentuk dan struktur hutan kota selong dari keduanya Taman Rinjani dan Taman tugu yaitu memiliki bentuk bergerombol atau menumpuk, yaitu hutan kota dengan komunitas vegetasinya terkonsentrasi pada suatu areal dengan jumlah vegetasinya minimal 100 pohon dengan jarak tanam rapat yang tidak beraturan dengan struktur tumbuhan kecil, sedang dan besar, 2. Hasil dari responden yang berada di Taman Rinjani Kota Selong dengan hasil persentase tertinggi dari : aspek ekologis yaitu Baik 39\%, aspek lanskap yaitu Baik 35\%, dan aspek estetik yaitu Baik 44\% Sedangkan di Taman Tugu Kota Selong aspek ekologi yaitu Cukup Baik 46\%, aspek lanskap yaitu Baik $42 \%$ dan aspek estetika yaitu Baik $45 \%$.
\end{abstract}

\section{Key words : Identifikasi Bentuk Struktur Dan Peran Hutan Kota Selong}

\section{PENDAHULUAN}

Perkembangan kawasan perkotaan di Indonesia bergerak sangat cepat dan hal ini diindikasikan oleh semakin meningkatnya jumlah penduduk yang tinggal dan beraktivitas di wilayah perkotaan.Pertambahan jumlah penduduk yang tidak diiringi oleh peningkatan daya dukung lingkungan dapat mengakibatkan timbulnya masalah perkotaan seperti meningkatnya suhu udara dan penurunan kualitas lingkungan.Permasalahan kerusakan lingkungan hidup dapat diatasi dengan keberadaan Ruang Terbuka Hijau (RTH). Ruang terbuka hijau merupakan ruang alami yang menjadi bagian yang penting bagi suatu kota berkaitan dengan penanggulangan berbagai masalah perkotaan (Zoer'aini, 2005).Keberadaan RTH sangat diperlukan bagi wilayah perkotaan.Adanya RTH diharapkan mampu menanggulangi permasalahan lingkungan perkotaan terutama dalam menetralisir dampak negatif yang disebabkan oleh aktivitas perkotaan.RTH mempunyai manfaat terhadap komponen lingkungan diantaranya menyerap panas, mengurangi tingkat kebisingan dan pencemaran udara.RTH melalui perannya sebagai pengatur iklim mikro dapat menurunkan suhu permukaan yang secara langsung berpengaruh terhadap sebaran suhu udara dan dapat meningkatkan kenyamanan hidup masyarakat (Ahmad dkk, 2012). Hutan Kota Selong merupakan salah satu RTH di Kabuvaten Lombok timur yang memiliki luas 1,70 ha. Hutan kota ini tidak hanya dapat difungsikan sebagai kawasan resapan air tetapi juga dijadikan sebagai ruang aktivitas publik yang berbasis pelestarian kawasan hijau. Keberadaan hutan kota ini menjadi suatu komponen penting dalam mempertahankan kenyamanan kota bagi penduduknya melalui fungsinya dalam 
menjaga hutan kota. Hutan kota dapat dijadikan sebagai ruang aktivitas publik. Ruang aktivitas publik yang baik harus nyaman karena nyamannya suatu RTH akan meningkatkan produktifitas orang didalamnya. Aspek kenyamanan pada hutan kota adalah suhu udara, kelembaban udara dan fasilitas. Untuk mengetahui efektivitas fungsi hutan kota dalam memberikan kenyamanan terhadap masyarakat, maka diperlukan penelitian tentang

IDENTIFIKASI BENTUK, STRUKTUR DAN PERAN HUTAN KOTA SELONG METODOLOGI PENELITIAN

Penelitian ini dilaksanakan di hutan kota selong kecamatan selong kabupaten Lombok timur. Penelitian ini dilaksanakan selama satu bulan pada bulan januari 2020 .

\section{a. Alat dan Bahan}

1. Alat tulis

2. Kamera untuk pengambilan gambar

3. Wawancara

4. Peta

b. Batas Penelitian

1. Wilayah yang diteliti adalah Hutan Kota selong.

2. Kenyamanan lingkungan yang akan dikaji dalam penelitian ini dibatasi pada pengunjung.

\section{c. Jenis Data}

1. Data Primer

Data primer merupakan sumber data yang diperoleh langsung dari sumber asli (tidak melalui media perantara).Data primer dapat berupa opini subyek (orang) secara individual atau kelompok, hasil observasi terhadap suatu benda (fisik), kejadian atau kegiatan, dan hasil pengujian.Data primer biasanya diperoleh dari responden. Responden adalah orang yang dimintai memberikan keterangan tentang suatu fakta atau pendapat. Keterangan tersebut disampaikan dalam bentuk tulisan yaitu ketika mengisi angket, lisan ketika menjawab wawancara (Arikunto, 2002) Adapun cara untuk memproleh data primer melalui :

A. Observasi

Metode ini dilakukan dengan cara melakukan pengamatan secara langsung terhadap fenomena yang akan diteliti. Dimana dilakukan pengamatan atau pemusatan perhatian terhadap obyek dengan menggunakan seluruh alat indera.Jadi mengobservasi dapat dilakukan melalui penglihatan, pendengaran, peraba dan pengecap (Arikunto, 1997). Dalam penelitian ini, peneliti melakukan pengamatan dan pencatatan data secara sistematik.

\section{B. Wawancara}

Wawancara dalam penelitian ini menggunakan kuisoner, kuisioner adalah daftar pertanyaan tertulis yang diberikan kepada subjek yang diteliti untuk mengumpulkan informasi yang di butuhkan peneliti. Kuisioner ada dua macam yaitu: kuisioner bersetruktur atu bentuk tertutup dan kuisioner tidak bersetruktur atau terbuka. Kuisioner tertutup berisikan pertanyaan yang disertai dengan pilihan jawaban.Kuisioner terbuka berisi pertanyaan yang tidak di sertai jawaban. Menurut Kusumah (2011:78).

Kuisioner yang digunakan dalam penelitian ini yaitu: kuisioner tertutup yang berisikan pertanyaan yang disertai dengan pilihan jawaban.

\section{Data Sekunder}

Data sekunder merupakan sumber data penelitian yang diperoleh peneliti secara tidak langsung melalui media perantara (diperoleh dan dicatat oleh pihak lain). Data sekunder umumnya berupa bukti, catatan atau laporan historis yang telah tersusun dalam arsip (data dokumenter) yang dipublikasikan dan yang tidak dipublikasikan, literatur, media cetak (Arikunto, 2002).

\section{d. Metode Pengambilan Data}

1. Tehnik pengumpulan data

Untuk mengetahui dan mendeskripsikan bentuk dan struktur hutan kota melalui surve lapangan. Untuk data peranan hutan kota diperoleh dengan penyebaran kuisoner kepada masyarakat sekitar kawasan, yang dipilih secara eksidentil pengunjung yang ada pada saat penelitian dilakukan.

2. Teknik analisis data

Kuisoner terkait fungsi hutan kota yaitu: aspek ekologis, aspek lansekap dan aspek estetika, ditabulasikan dalam bentuk table 
sekor. Penentuan katagori penilaian dipergunakan berdasarkan skala likrets Klasifikasi penilaian ada 5 tingkat nilai 1 (sangat tidak baik), 2 (tidak baik), 3 (cukup baik), 4 (baik), 5 (sangat baik). Penentuan klas nilai ini dengan menentukan range nilai rata-rata. Range nilai rata-rata $=$ selisih nilai rata-rata tertinggi dengan nilai rata-rata terendah, sebagai dasar penentuan klasifikasi penelitian.

\section{HASIL dan PEMBAHASAN}

\section{A. Hasil}

\section{kondisi umum lokasi penelitian \\ 1. letak luas penelitian}

Secara geografis wilayah Kota Selong

Kecamatan Selong Kabupaten Lombok Timur terletak di utara wilayah Kecamatan Suralaga dengan batas-batas wilayah :

Sebelah Utara : Kecamatan Suralaga

Sebelah Selatan : Kecamatan Sakra

Sebelah Barat : Kecamatan Labuan haji

Sebelah Timur: Kecamatan Sukamulia

Luas wilayah Kecamatan Selong adalah seluas $31,68 \mathrm{~km} 2$ dan terdiri dari 11Kelurahan dan 1 desa, Tinggi kecamatan selong dari permukaan air laut 74-192 meter.

\section{Iklim Dan Struktur Tanah}

Berdasarkan pada iklimya, kawasan perkotaan selong mempunyai iklim tropis dengan temperature udara yang cukup tinggi (24-31 $\left.{ }^{\circ} \mathrm{C}\right)$. Jumlah bulan basah berkisar antara 3-4 bulan dan bulan kering 4-6 bulan atau dengan kata lain bulan basah lebih pendek dari bulan kering. Sedangkan bulan lembab berkisar antara 1-2 bulan. Di perkotaan selong setuasi musim hujan mulai pada bulan oktober samapai awal November atau paling lambat bulan ahir bulan desember dengan curah hujan rata-rata $132,10 \mathrm{~mm}$.

Berdasarkan jenis tanahnaya wilayah perkotaan selong masih tercakup dalam geologi dikabupaten Lombok timur, berdasarkan pada hal tersebut maka jenis batuan di perkotaan selong adalah batuan vulkanis, endapan dan struktur tanah diperkotaan selong secara umum terdiri dari jenis tanah grumoso, alluvial kelabu, coklat regosol kelabu dan alluvial hidromof.
3. Jumlah Penduduk Kota Selong

Tabel 1. Jumlah Penduduk

\begin{tabular}{|c|c|c|}
\hline NO & PENDUDUK & JUMLAH \\
\hline 1 & Laki - Laki & 40.674 Jiwa \\
\hline 2 & Perempuan & 40.240 Jiwa \\
& & \\
\hline & Total & 80.914 Jiwa \\
\hline
\end{tabular}

Sumber : proyeksi BPS kab.Lombok Timur

Dari tabel diatas jumlah penduduk

Kota Selong berjumlah 80.914 jiwa dari jumlah penduduk laki - laki 40.674 jiwa dan jumlah penduduk perempuan berjumlah 40.240 jiwa.

Lampiran Gambar.1.Peta Kota Selong.

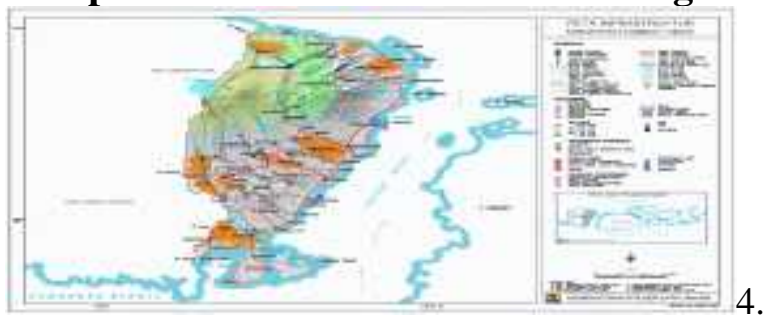

Sumber Data : 2019

\section{Identifikasi Bentuk Dan Struktur Hutan Kota Selong}

Bentuk hutan kota menurut Irwan (1994) dapat di kelompokkan menjadi 3 bentuk, yaitu : 1. Bergerombol atau menumpuk, yaitu hutan kota dengan komunitas vegetasinya terkonsentrasi pada suatu areal dengan jumlah vegetasinya minimal 100 pohon dengan jarak tanam rapat yang tidak beraturan, 2) menyebar yaitu hutan kota yang tidak tidak mempunyai pola tertentu, dengan komunitas vegetasinya tumbuh menyebar terpencar-pencar dalam bentuk rumpun atau gerombol-gerombol kecil, 3) berbentuk jalur, yaitu komunitas vegetasinya tumbuh pada lahan yang berbentuk jalur lurus atau melengkung, mengikuti bentuk sungai, jalan, pantai saluran dan sebagainya.

Berdasarkan Marini (1996), bentuk hutan kota dibagi menjadi 4 bentuk yakni 1) taman, 2) pekarangan/kebun. 3) jalur hijau dan 4) hutan yang terletak di areal konservasi kota. 
Terdapat 2 hutan kota yang berbentuk taman kota yang ada di kota selong yaitu taman Rinjani Kota Selong dan Taman Tugu Kota Selong

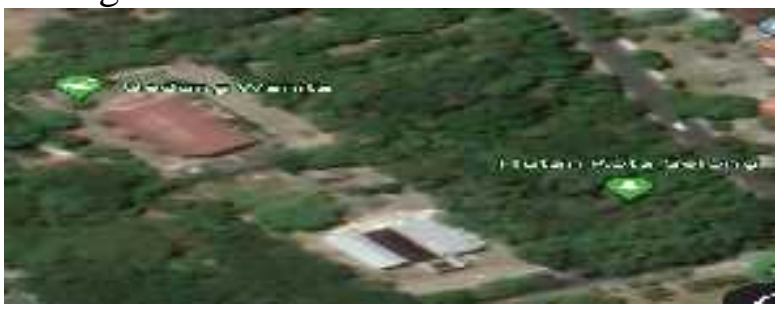

Struktur hutan kota selong memiliki jenis tumbuhan dengan ukuran pohon kecil, sedang dan besar. Adapun nama-nama jenis pohon pada hutan selong :

\begin{tabular}{|c|c|c|c|}
\hline No & $\begin{array}{l}\text { Nama } \\
\text { Jenis } \\
\text { Pohon }\end{array}$ & $\begin{array}{l}\text { Jumlah } \\
\text { Pohon }\end{array}$ & Nama Latin \\
\hline 1 & Bajur & 18 & $\begin{array}{l}\text { Pterospermum } \\
\text { Javanicum }\end{array}$ \\
\hline 2 & Jati Putih & 15 & $\begin{array}{l}\text { Gmelina } \\
\text { Arborea }\end{array}$ \\
\hline 3 & Leda & 26 & $\begin{array}{l}\text { Eucalyptus } \\
\text { Deglupta }\end{array}$ \\
\hline 4 & Trembesi & 24 & $\begin{array}{l}\text { Samanea } \\
\text { Saman }\end{array}$ \\
\hline 5 & Angsana & 15 & $\begin{array}{l}\text { Pterocarpus } \\
\text { Indicus }\end{array}$ \\
\hline 6 & Akasia & 18 & Acacia \\
\hline 7 & Mahoni & 25 & $\begin{array}{l}\text { Swietenia } \\
\text { Mahagoni }\end{array}$ \\
\hline 8 & Kenari & 8 & $\begin{array}{l}\text { Canarium } \\
\text { Ovatum }\end{array}$ \\
\hline 9 & Sawo Susu & 7 & $\begin{array}{c}\text { Chrysophyllum } \\
\text { Cainito }\end{array}$ \\
\hline 10 & $\begin{array}{l}\text { Palem } \\
\text { Kuning }\end{array}$ & 1 & $\begin{array}{c}\text { Dypsis } \\
\text { Lutescens }\end{array}$ \\
\hline 11 & Pilisium & 5 & Pinisium \\
\hline 12 & $\begin{array}{c}\text { Beringin } \\
\text { Karet }\end{array}$ & 10 & Ficus Elastica \\
\hline 13 & Kenanga & 3 & $\begin{array}{l}\text { Cananga } \\
\text { Odorata }\end{array}$ \\
\hline 14 & Gelodokan & 89 & $\begin{array}{l}\text { Polyalthia } \\
\text { Longifolia }\end{array}$ \\
\hline 15 & Sengon & 30 & $\begin{array}{c}\text { Albizia } \\
\text { Chinensis }\end{array}$ \\
\hline 16 & $\begin{array}{l}\text { Palem } \\
\text { Raja }\end{array}$ & 4 & $\begin{array}{l}\text { Roystonea } \\
\text { Regia }\end{array}$ \\
\hline
\end{tabular}

\begin{tabular}{|c|c|c|c|}
\hline 17 & Sawo & 4 & $\begin{array}{c}\text { Manilkara } \\
\text { Zapota }\end{array}$ \\
\hline
\end{tabular}

5. Identifikasi Bentuk Dan Struktur Taman Rinjani Kota Selong

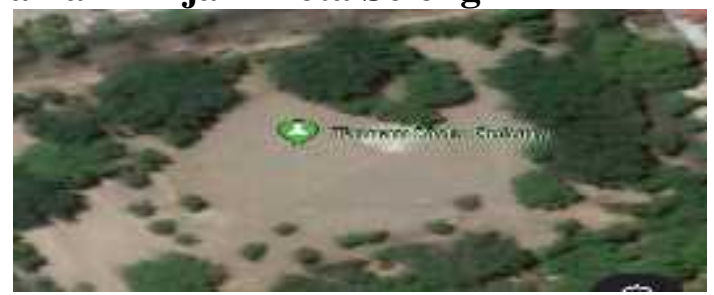

Bentuk dari Taman Rinjani kota selong memiliki tipe bergerombol atau menumpuk, yaitu hutan kota dengan komunitas vegetasinya terkonsentrasi pada suatu areal dengan jumlah vegetasinya minimal 100 pohon dengan jarak tanam rapat yang tidak beraturan

Struktur dari taman rinjani kota selong memiliki jenis tumbuhan dengan ukuran pohon kecil, sedang dan besar.

\section{Identifikasi Bentuk Dan Struktur Taman} Tugu Kota Selong

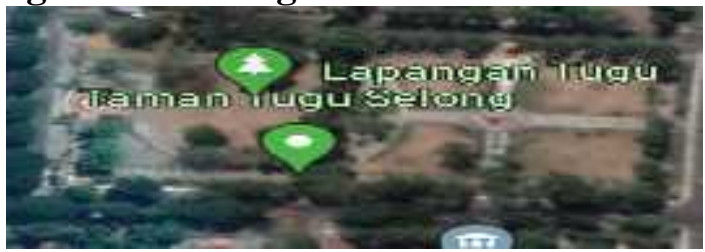

Bentuk dari taman tugu sama dengan bentuk hampirsama dengan taman Rinjani yaitu bergerombol atau menumpuk, yaitu hutan kota dengan komunitas vegetasinya terkonsentrasi pada suatu areal dengan jumlah vegetasinya minimal 100 pohon dengan jarak tanam rapat yang tidak beraturan dan Memiliki lebih dari Sembilan komposisi tanaman pepohonan yang tinggi dikombinasikan dengan semak dan perumputan, dan berfungsi jugak sebagai penyerap pencemaran udara.

\section{Manfaat Hutan Kota \\ Menurut Irwan}

mengemukakan bahwa hutan kota adalah komunitas vegetasi berupa pohon dan asosianya yang tumbuh dilahan kota atau sekitar kota baik membentuk jalur yang menyebar atau bergerombol (menumpuk) dengan struktur meniru atau (menyerupai) hutan alam, membentuk habitat yang memungkinkan kehidupan bagi satwa dan 
menimbulkan lingkungan sehat, nyaman, dan estetis.

Secara garis besar fungsi hutan kota dapat dikelompokkan dalam tiga fungsi yaitu Fungsi 1) lansekap ( Fungsi fisik, fungsi social dan fungsi kesehatan), 2) Fungsi Pelestarian lingkungan (ekologi), dan 3) fungsi estetika ( Irwan, 1994)

\section{Aspek Ekologis Taman Rinjani Kota} Selong

Persepsi masyarakat pada aspek ekologis dari 9 pertanyaan yang diberikan kepada 15 responden secara random pada hari jumat 31 januari 2020 di Taman Rinjani mendapatkan hasil 5\% Sangat Tidak Baik ( STB), 12\% Tidak Baik ( TB), 33\% Cukup Baik (CB), 39\% Baik (B), 11\% Sangat Baik (SB). Prosentase tertinggi adalah baik yaitu 39\% Sehingga dapat diartikan bahwa masyarakat merasa bahwa peran dari taman Rinjani kota selong berperan baik secara ekologis dan berpengaruh secara nyata terhadap kehidupan dan kelestarian lingkungan huni mereka. Masyarakat sekitar merasa lingkungan menjadi lebih nyaman, sejuk dan segar semenjak adanya hutan taman kota selong, sehingga terhindar dari bencana alam seperti banjir, longsor, dan kekurangan air bersih.

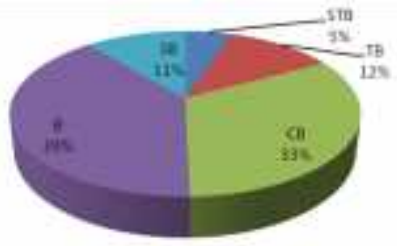

Keterangan :

Sangat Tidak Baik : $: 5 \%$

Tidak Baik $\quad: 12 \%$

Cukup Baik $\quad: 33 \%$

Baik $: 39 \%$

Sangat Baik $\quad: 11 \%$

\section{Aspek Lanskap Taman Rinjani Kota} Selong.

Pandangan masyarakat pada aspek lansekap yang diwakili 6 pertanyaan yang diberikan kepada 15 responden secara random di Hutan Taman Rinjani Kota Selong mendapatkan hasil persentasi 6\% Sangat Tidak Baik (STB), 4\% Tidak Baik(TB), 28\% Cukup Baik (CB), 35\% Baik (B), 27\%
Sangat Baik (SB). Prosentasi tertinggi adalah pada baik yaitu $35 \%$, Sehingga dapat diartikan bahwa taman kota selong dalam aspek lansekap berperan dalam pendidikan, rekreasi, meredam kebisingan dan olah raga serta memiliki keindahan bagi masyarakat kota selong. Dimana masyarakat setempat merasa taman Rinjani kota selong dapat dijadikan tempat rekreasi, memberikan keteduhan, dapat mengurangi polusi asap kendaraan, dapat menjadi tempat penelitian, serta dapat menjadi tempat belajar yang seru.

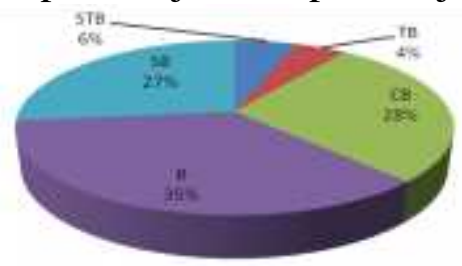

Keterangan :

Sangat Tidak Baik : $6 \%$

Tidak Baik $\quad: 4 \%$

Cukup Baik $\quad: 28 \%$

Baik $\quad: 35 \%$

Sangat Baik $\quad: 27 \%$

3.Aspek Estetika Taman Rinjani Kota Selong.

Aspek estetika yang diwakili dari 3 pertanyaan yang diberikan kepada 15 responden secara random pada hari jumat 31 januari 2020 di Hutan taman kota selong mendapatkan hasil persentase, 5\% Sangat Tidak Baik (STB), 9\% Tidak Baik (TB), 22\% Cukup Baik (CB), 44\% Baik (B), 20\% Sangat Baik (SB). Dari prosentase memiliki nilai tertinggi adalah baik yaitu $44 \%$, sehinga dapat di artikan bahwa taman hutan kota selong dalam aspek estetika berperan baik di kehidupan masyarakat setempat. Dimana masyarkat stempat mersasa taman hutan kota selong dapat memberikan sebagai bembentuk ruang, pengendalian suhu udara, dan memperbaiki kondisi tanah.

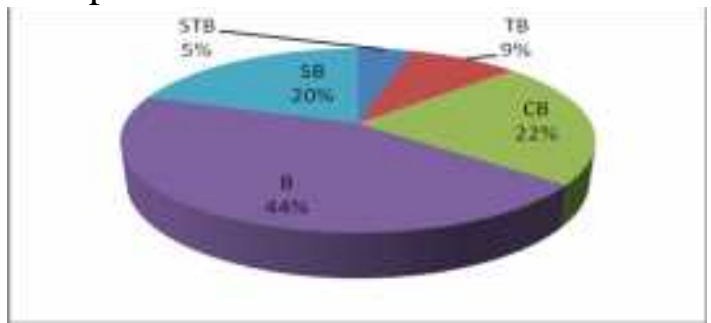

Keterangan :

Sangat Tidak Baik : $5 \%$ 
Tidak Baik $\quad: 9 \%$

Cukup Baik : $22 \%$

Baik : $44 \%$

Sanagt Baik $\quad: 20 \%$

1.Aspek Ekologis Taman Tugu Kota Selong.

Persepsi masyarakat pada aspek ekologis dari 9 pertanyaan yang diberikan kepada 15 responden secara random mendapatkan hasil 7\% Sangat Tidak Baik ( STB), $17 \%$ Tidak Baik ( TB), 46\% Cukup Baik (CB), 34\% Baik (B), 6\% Sangat Baik (SB). Prosentase tertinggi adalah cukup baik yaitu $46 \%$ dan disusul dengan baik yaitu $34 \%$, Sehingga dapat diartikan bahwa masyarakat merasa bahwa peran dari taman Tugu Kota Selong berperan baik secara ekologis dan berpengaruh secara nyata terhadap kehidupan dan kelestarian lingkungan huni mereka. Masyarakat sekitar merasa lingkungan menjadi lebih nyaman, sejuk dan segar semenjak adanya hutan taman kota selong.

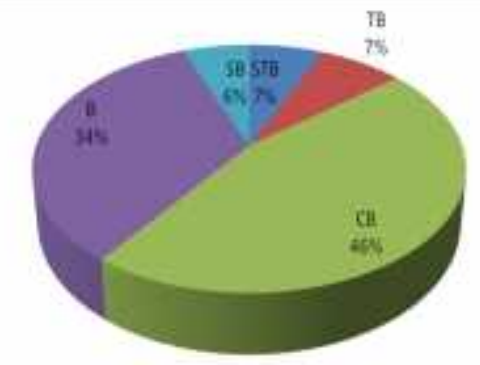

Keterangan :

Sangat Tidak Baik : $7 \%$

Tidak Baik $\quad: 7 \%$

Cukup Baik $\quad: 46 \%$

Baik : $34 \%$

Sanagt Baik $\quad: 6 \%$

2.Aspek Lanskap Taman Tugu Kota Selong.

Pandangan masyarakat pada aspek lansekap yang diwakili 6 pertanyaan yang diberikan kepada 15 responden secara random, mendapatkan hasil persentasi $8 \%$ Sangat Tidak Baik (STB), 3\% Tidak Baik(TB), 25\% Cukup Baik (CB), 42\% Baik (B), 22\% Sangat Baik (SB). Prosentase tertinggi adalah baik yaitu $42 \%$, Sehingga dapat diartikan bahwa taman Tugu kota selong dalam aspek lanskap berperan baik. Dimana masyarakat setempat merasa taman Tugu kota selong dapat dijadikan tempat pendidikan, rekreasi, Mengurangi kebisingan, memberikan keteduhan, dapat mengurangi polusi asap kendaraan, sebagai sarana olahraga dan dapat menjadi tempat penelitian, serta dapat menjadi tempat memiliki keindahan.

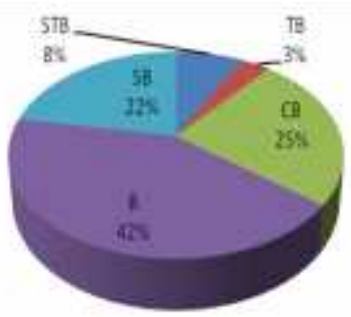

Keterangan :

Sangat Tidak Baik : :8\%

Tidak Baik : $3 \%$

Cukup Baik : $: 25 \%$

Baik : $42 \%$

Sanagt Baik $: 22 \%$

3.Aspek Estetika Taman Tugu Kota Selong.

Aspek estetika yang diwakili dari 3 pertanyaan yang diberikan kepada 15 responden secara random pada hari jumat 31 januari 2020 di Hutan taman kota selong mendapatkan hasil persentase, 9\% Sangat Tidak Baik (STB), 4\% Tidak Baik (TB), 29\% Cukup Baik (CB), 45\% Baik (B), 13\% Sangat Baik (SB). Prosentase tertinggi adalah baik yaitu $45 \%$, Sehinga dapat di artikan bahwa taman Tugu kota selong dalam aspek estetika yang baik di kehidupan masyarakat setempat. Dimana masyarkat stempat merasa taman Tugu kota selong dapat memberikan keindahan bagi sekitar, sebagai pengendalian suhu udara, dan memperbaiki kondisi tanah.

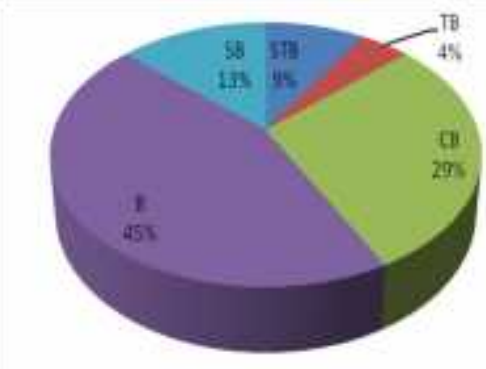

Keterangan :

Sangat Tidak Baik : :9\%

Tidak Baik : $4 \%$

Cukup Baik : $29 \%$

Baik : $45 \%$

Sanagt Baik $\quad: 13 \%$

Kesimpulan 
1. Bentuk dan struktur hutan kota selong dari keduanya Taman Rinjani dan Taman tugu yaitu memiliki bentuk bergerombol atau menumpuk, yaitu hutan kota dengan komunitas vegetasinya terkonsentrasi pada suatu areal dengan jumlah vegetasinya minimal 100 pohon dengan jarak tanam rapat yang tidak beraturan dengan struktur tumbuhan kecil, sedang dan besar.

2. Hasil dari responden yang berada di Taman Rinjani Kota Selong dengan hasil persentase tertinggi dari : aspek ekologis yaitu Baik 39\%, aspek lanskap yaitu Baik 35\%, dan aspek estetik yaitu Baik 44\% Sedangkan di Taman Tugu Kota Selong aspek ekologi yaitu Cukup Baik 46\%, aspek lanskap yaitu Baik $42 \%$ dan aspek estetika yaitu Baik $45 \%$.

\section{Saran}

1. Diharapkan kepada dinas lingkungan hidup dan kehutanan, pemerintah kota selong dapat melakukan peningkatan prawatan dan pemeliharaan hutan kota dan taman kota selong supaya menjadi lebih baik dari sebelumnya.

2. Ketersediaan tempat sampah masih kurang dan tidak tertata dengan rapi, seta ketersediaan lahan parkir sehingga tidak menyerminkan keindahan.

3. Penataan ulang untuk pedagang yang menempati lokasi taman kota selong.

\section{DAFTAR PUSTAKA}

Ahmad, F., Arifin, H., Dahlan, E., Effendy, S., dan Kurniawan, R. 2012.Analisis hubungan luas ruang terbuka hijau (rth) dan perubahan suhu di Kota Palu. Jurnal Hutan Tropis. 13(2):173180.

Brooks, R. G. 1988. Site Planning :Evaluation, Process, and Development. Buku.Prentice Hall. New Jersey. 322 p.

Dahlan.2011. Potensi Hutan Kota Sebagai Alternatif Substitusi Fungsi Alat
Pendingin Ruangan.Skripsi.Institut Pertanian Bogor. Bogor. 65 p.

Dahlan, E.N. 1992. Hutan Kota untuk Pengelolaan dan Peningkatan Kualitas Lingkungan Hidup.Buku.Asosiasi Pengusaha Hutan Indonesia (APHI). Jakarta. 92 p.

Gates, D. M. 1972. Man and His Enviroment : Climate. Buku.Harper and Row. New York. 175p.

Grey, W. G., dan Deneke. 1978. Urban Forestry. Buku.John Wiley and Sons. New York. 279 p.

Gunawan, W. 1999.Persepsi Dan Perilaku Ekonomi Masyarakat Desa Sinarasa Terhadap Pelestarian Sumberdaya Hutan Taman Nasional Gunung Halimun.Skripsi.Institut Pertanian Bogor. Bogor. 77 p.

Handoko. 1994. Klimatologi Dasar. Buku. Pustaka Jaya. Bogor. 192 p.

Irwan, Z. D. 2005. Tantangan Lingkungan dan Lansekap Hutan Kota.Buku. Bumi Aksara. Jakarta. 300 p.

Irwan, S.N.R., Kharuddin. 2010. Studi kenyamanan untuk aktivitas di lanskap Hutan Kota UGM. Jurnal Ilmu Kehutanan. 4(2) : 105-112.

Kartasapoetra, A. G. 2006. Klimatologi : Pengaruh Iklim Tehadap Tanah dan Tanaman. Buku. Bumi Aksara. Jakarta. 113 p.

Lakitan, B. 1994.Dasar-dasar Klimatologi.Buku.Raja Grafindo Persada.Jakarta 173 p.

Laurie, M. 1986. Pengantar Kepada Arsitektur Pertamanan. Buku.Multi Mata Media. Bandung. 133 p. 
Lay dan Bey, A. 1990. Metode Kausal dan Time Series Dalam Analisis Data Iklim.Buku.Institut Pertanian Bogor.75 p.

Marini A., 1096. Pokok-pokok Perhutanan Kota. Fakultas Kehutanan. Institut Pertanian Bogor. Bogor

Prasetyo, I. 1997. Studi iklim mikro jalur hijau di Kotamadya Bandung.Skripsi.Intutut Pertanian Bogor. Bogor. 69 p.

Prawirowardoyo, $\quad$ S. 1996. Meteorologi.Buku.ITB. Bandung. 226 p.

Santoso, M. E. 1986. Alat Pengukur Cuaca. Buku.Institut Pertanian Bogor. Bogor. $95 \mathrm{p}$.

Simonds, J. O. 1983. Landscape Architecture.Buku. Mc Graw-Hill. New York :. 396 p.

Sosrodarsono dan Takeda. 1999. Hutan Kota : Peranan dan Permasalahannya. Buku.Institut Pertanian Bogor. Bogor. $125 \mathrm{p}$.

Windawari, N. W. 1994. Persepsi Pelajar SMA di Kotamadya Jogja Tentang Lingkungan Hijau Perkotaan.Skripsi.Institut Pertanian Bogor. Bogor. 56 p.

Zoer’aeni, 2005.Tantangan Lingkungan dan Lansekap Hutan Kota.Buku. Bumi 